\title{
Aplikasi Sistem Penjualan Sparepart Motor Pada Bengkel Barokah Motor Berbasis Web
}

\author{
Aris ${ }^{1}$ \\ Mochamad Rinja ${ }^{2}$ \\ Taufan Jherico ${ }^{3}$ \\ Dosen STMIK Raharja ${ }^{1}$, Mahasiswa STMIK Raharja ${ }^{2,3}$ \\ E-mail : aris@raharja.info ${ }^{1}$,rinja@raharja.info ${ }^{2}$,taufan.jherico@raharja.info ${ }^{3}$
}

\begin{abstract}
ABSTRAK
Bengkel Barokah Motor merupakan salah satu usaha keluarga yang bergerak dibidang retail dengan menjual sparepart motor. Proses administrasi penjualan merupakan salah satu kegiatan penting bagi proses penjualan sparepart motor di bengkel ini. Untuk mendukung sistem aplikasi penjualan ini, perlu adanya sistem komputerisasi untuk membuat laporan penjualan yang cepat, akurat serta efisien dalam pengerjaannya. Namun dalam kenyataannya, hal tersebut memang tidak sesuai dengan keinginan dan harapan yang ditentukan, karena belum adanya sistem komputerisasi yang digunakan di bengkel tersebut. Bengkel Barokah Motor masih menggunakan sistem manual dalam pengolahan data administrasinya. Sehing ga masih seringnya terjadi kesalahan pada saat pencatatan data. Untuk itu perlu dirancang suatu sistem aplikasi penjualan. Sistem tersebut dirancang menggunakan metode $O O A D$, dan digambarkan melalui diagram UML seperti activity diagram, sequence diagram, use case diagram, class diagram dan state chart diagram. Sistem dibangun menggunakan bahasa pemrograman PHP, dan database yang digunakan adalah MySQL. Hasil penelitian ini adalah sebuah sistem aplikasi penjualan yang digunakan untuk mencatat setiap transaksi yang terjadi serta membuat laporan penjualan secara cepat dan akurat. Sehingga dengan adanya sistem tersebut, user akan sangat terbantu dalam mengerjakan pekerjaannya.
\end{abstract}

Kata kunci : aplikasi sistem penjualan, sparepart motor

\section{ABSTRACT}

Workshop Barokah Motor is one of the family businesses engaged in retail selling motor spare parts. Sales administration process is one of the important activities for motor spare parts sales process at this workshop. To support this sales application systems, the need for a computerized system to create sales reports are fast, accurate and efficient in the process.But in reality, it does not correspond with the wishes and expectations are determined, due to the lack of computerized systems used in the workshop. Workshop Barokah Motor still use manual systems in data processing administration. So it is still frequent errors during data recording. For that we need to design a system application sales. The system is designed using OOAD methods, and illustrated by diagrams like UML activity diagrams, sequence diagrams, use case diagram, class diagram and state chart diagrams. The system is built using the PHP programming language, and the database used is MYSQL. The result of this research is a sales application system used to record each transaction and create sales reports quickly and accurately. So with such a system, the user will be greatly helped in doing his job

95| Aris, Mochamad, Taufan - Aplikasi Sistem Penjualan Sparepart... 
Keyword: App sales system, motor spare parts

\section{PENDAHULUAN}

Di teknologi saat ini, menjadikan informasi memiliki peranan yang sangat penting dalam usaha menciptakan kemajuan disemua bidang kehidupan. Sehingga teknologi informasi telah banyak dirasakan kemudahan dalam mendapatkan informasi yang cepat. Perkembangan ilmu teknologi informasi pada saat ini sudah sangat meningkat, sehingga hampir semua manusia membutuhkan komputer dalam mengerjakan setiap pekerjaannya. Komputer memiliki peranan yang vital dalam memecahkan masalah khusus dalam pengolahan data, karena komputer memiliki kecepatan dan akurasi yang tinggi dalam pemrosesan data, sehingga dapat membantu pekerjaan manusia. Adanya Teknologi komputer sangat membantu dalam pemecahan pengolahan data. Penggunaan komputer juga dapat dijadikan alat untuk mencapai tujuan dan mencari kemudahan dalam melakukan suatu proses pekerjaan, terutama pekerjaan yang melibatkan banyak data. Hampir disemua instansi baik yang bersifat negeri maupun swasta telah menggunakan sistem teknologi komputer, bahkan tak jarang usaha-usaha kecil menengah telah memanfaatkan keberadaan system teknologi komputer.Namun pada kenyataannya masih banyak usaha-usaha yang belum menggunakan sistem terkomputerisasi dengan baik. Hal ini disebabkan karena masih kurangnya pengetahuan/minat pengusaha dengan sistem komputer. Padahal dengan sistem komputer, perusahaan dapat melakukan proses penyimpanan data dengan mudah, cepat dan rapi. Sehingga data dapat ditemukan kembali dengan cepat disaat kita membutuhkannya.

Saat ini semua kegiatan penjualan alat sparepart masih menggunakan sistem manual dimana setiap memasukkan data penjualan harus dilakukan satu-satu sehingga memakan waktu yang lama dan berpotensi adanya kesalahan memasukkan data pembelian alat sparepart.

\section{PERMASALAHAN}

Berdasarkan latar belakang pada judul penelitian diatas, maka dapat dirumuskan masalahmasalah yang akan dibahas sebagai berikut:

1. Bagaimana sistem penjualan sparepart motor di Bengkel Barokah Motor yang sedang berjalan pada saat ini?

2. Apa saja permasalahan yang terdapat dalam sistem penjualan sparepart yang sedang berjalan saat ini?

3. Bagaimana merancang sistem yang efektif dan efisien agar dapat memudahkan proses penjualan sparepart motor?

\section{METEDOLOGI PENELITIAN}

Dalam Proses Perancangan dan pembuatan system ini di perlukan beberapa tahap agar perencanaan dapat sesuai dengan baik dalam implementasinya. Banyak penelitian yang sebelumnya dilakukan mengenai Penjualan barang. Dalam upaya mengembangkan dan 
menyempurnakan system ini perlu dilakukan studi pustaka (literature review) sebagai salah satu dari penerapan metode penelitian yang telah dilakukan. yaitu:

a. Penelitian yang dilakukan oleh Rachma Nuary Achlani (2011) STMIK Raharja. Penelitian ini berjudul "Analisa Sistem Informasi Penjualan Barang Pada PD.E2 Premium Pusat Grosir Metro Tanah Abang, Jakarta Barat”. Penelitian ini dilakukan untuk mengetahui sistem penjualan yang terkomputerisasi dapat memudahkan kasir dalam pelayanan transaksi serta dapat menyajikan laporan secara cepat dan akurat.

b. Penelitian yang dilakukan oleh Andika Saputra (2012) STMIK Raharja.Penelitian ini berjudul "Analisa Sistem Penjualan Produk Fashion Pada J\&J Shop Tangerang". Penelitian ini dilakukan pada sebuah outlet dengan maksud membantu perusahaan dalam kelancaran proses penjualan yang selama ini sudah berjalan dengan baik, namun belum terkomputerisasi dalam pengelohan data dan informasi. Sehinga sering terjadi keterlambatan saat mengolah informasi dalam membuat laporan yang akan diserahkan kepada management.

\section{HASIL DAN PEMBAHASAN}

\section{Gambaran Sistem yang diusulkan}

\section{a. Use Case Diagram Yang Diusulkan}

Use case modelling berfungsi untuk menggambarkan sistem dengan pemakai luar (outside user) yang disebut actor. Use case diagram digunakan untuk menggambarkan hubungan interaksi antara sistem dan pemakai (user).

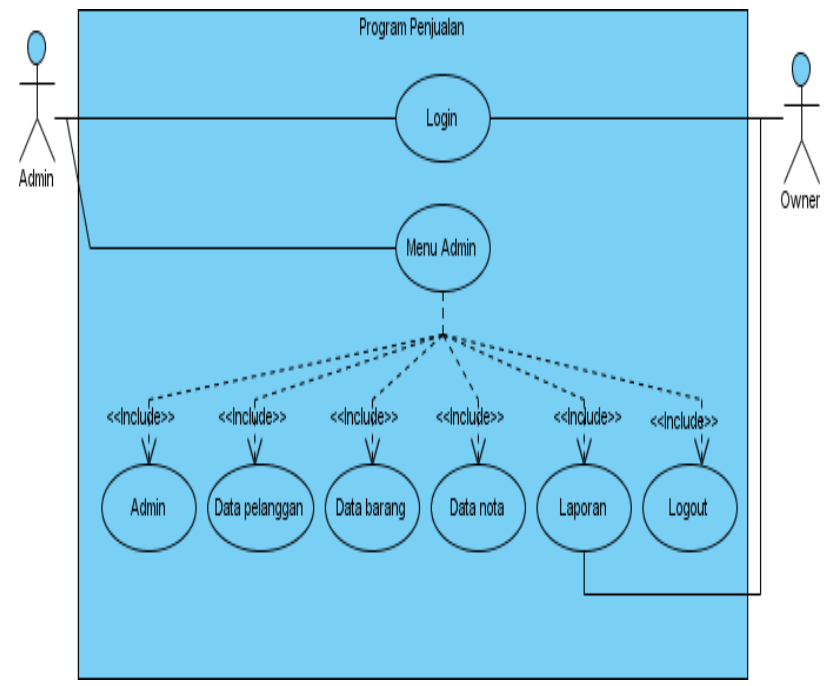

Gambar 1.Use Case Diagram Rancangan

Berdasarkan gambar 1, use case diagram yang diusulkan terdapat:

a. 1 sistem yang menjelaskan seluruh kegiatan penjualan sparepart di Bengkel Barokah Motor, yaitu program penjualan. 
b. 2 actor yang menggambarkan kegiatan, yaitu admin.

c. 3 use case yang dilakukan oleh actor, yaitu login, menu utama, dan logout.

d. 7 (tujuh) include, yaitu login benar, login salah, input data user, input data pelanggan, input data barang, cetak nota dan laporan penjualan

\section{b. Activity Diagram Yang Diusulkan}

Pada Activity diagram menggambarkan berbagai alur kegiatan dalam sistem yang dirancang dalam pembuatan Aplikasi ini.

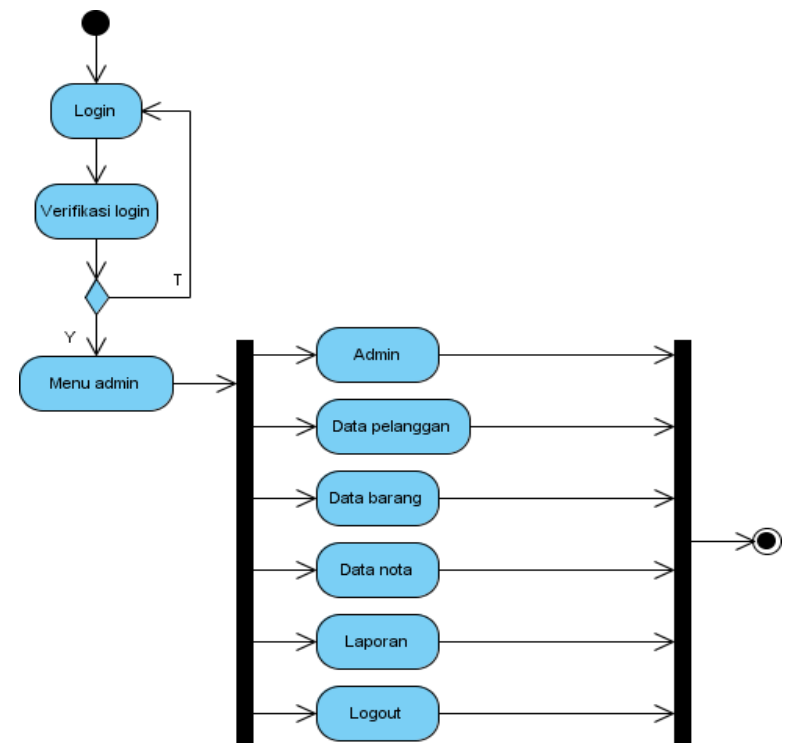

Gambar 2. Activity Diagram Admin

Berdasarkan gambar 2,activity diagram yang diusulkan untuk admin terdapat:

a. 1 (satu) initial node digunakan untuk memulai kegiatan.

b. 1 (satu) decision digunakan untuk pemilihan kondisi

c. 9 (sembilan) action, yaitu login, verifikasi login, menu utama, input data user, input data pelanggan, input data barang, cetak nota, laporan penjualan dan logout.

d. 2 (dua) fork node digunakan untuk percabangan action.

e. 1 (satu) final node digunakan untuk mengakhir kegiatan.

\section{c. Activity Diagram untuk owner}




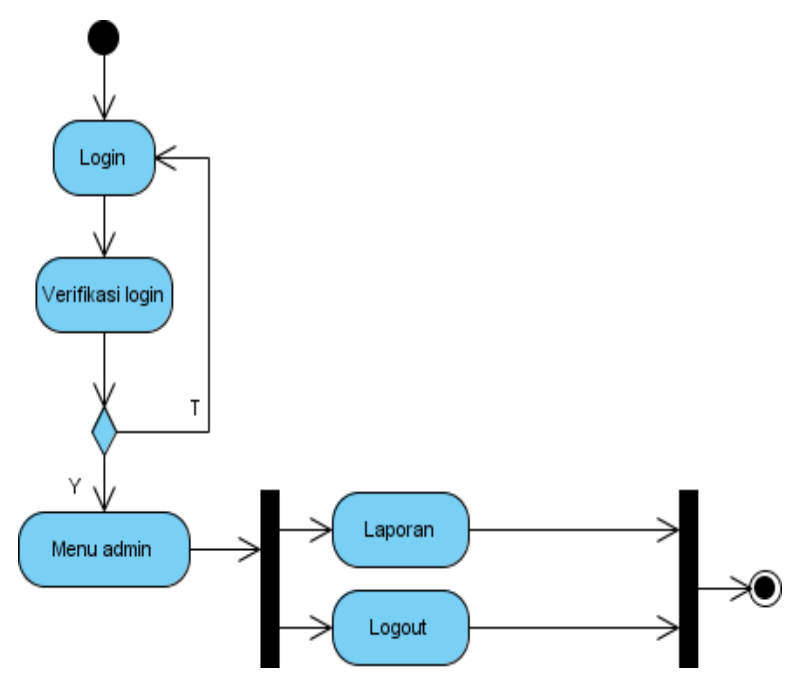

Gambar 3. Activity Diagram owner.

Berdasarkan gambar 3 activity diagram yang diusulkan untuk owner terdapat:

a.1 (satu) initial node digunakan untuk memulai kegiatan.

b. 1 (satu) decision digunakan untuk pemilihan kondisi

c.5 (lima) action, yaitu login, verifikasi login, menu utama, laporan penjualan dan logout.

d. 2 (dua) fork node digunakan untuk percabangan action.

e.1 (satu) final node digunakan untuk mengakhir kegiatan.

\section{d. Class Digram Yang Diusulkan}

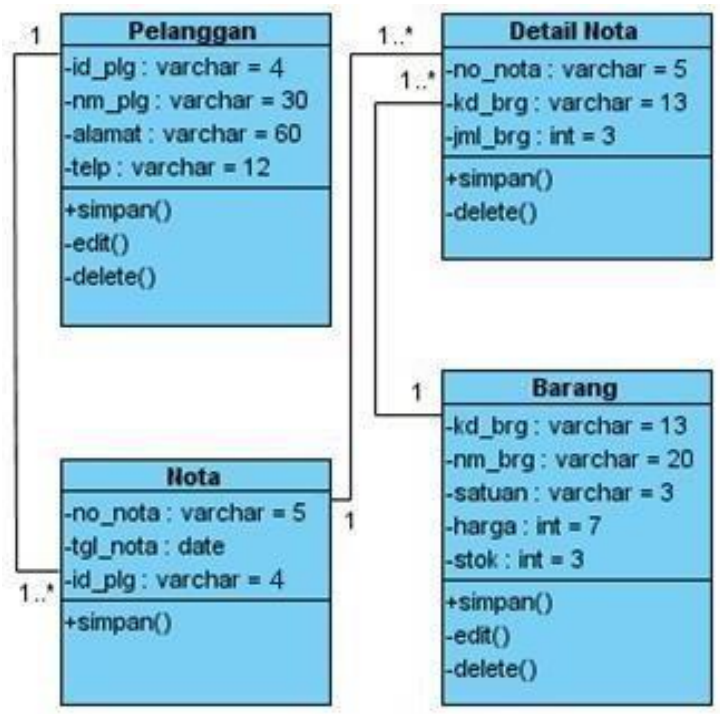

Gambar 4. Class Diagram

Pada gambar 4, pada class diagram yang dibuat terdapat 4 (empat) class, yaitu pelanggan, nota, detail nota dan barang. 


\section{Tampilan Program}

\section{a. Tampilan menu Untuk Login Admin}
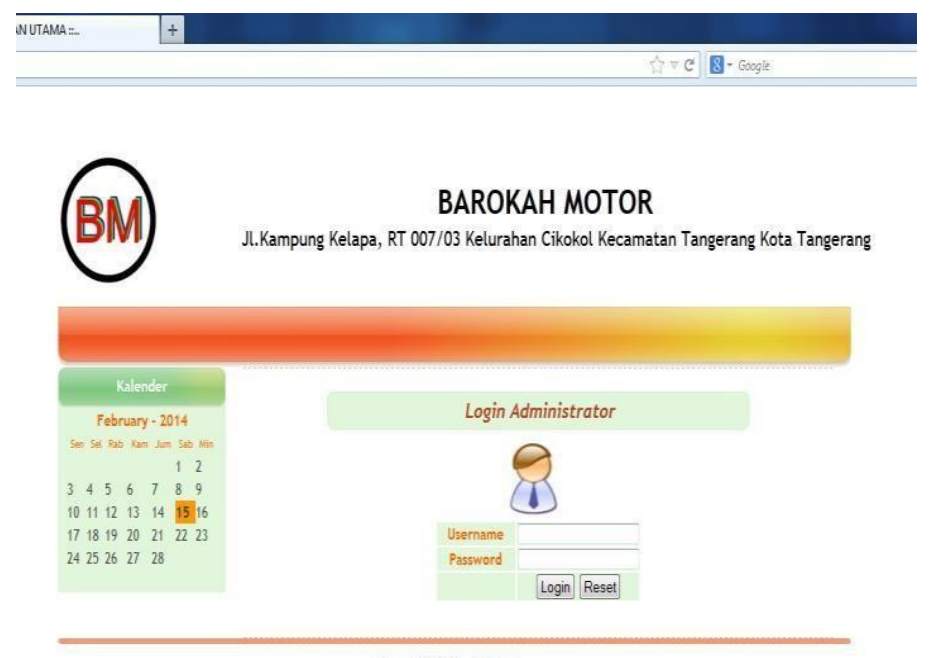

Gambar 5. Tampilan Login

Pada gambar 5,menampilkan tampilan awal untuk admin masuk ke area admin dalam mengelolah data transakasi.

\section{b. Tampilan Menu Area Admin}
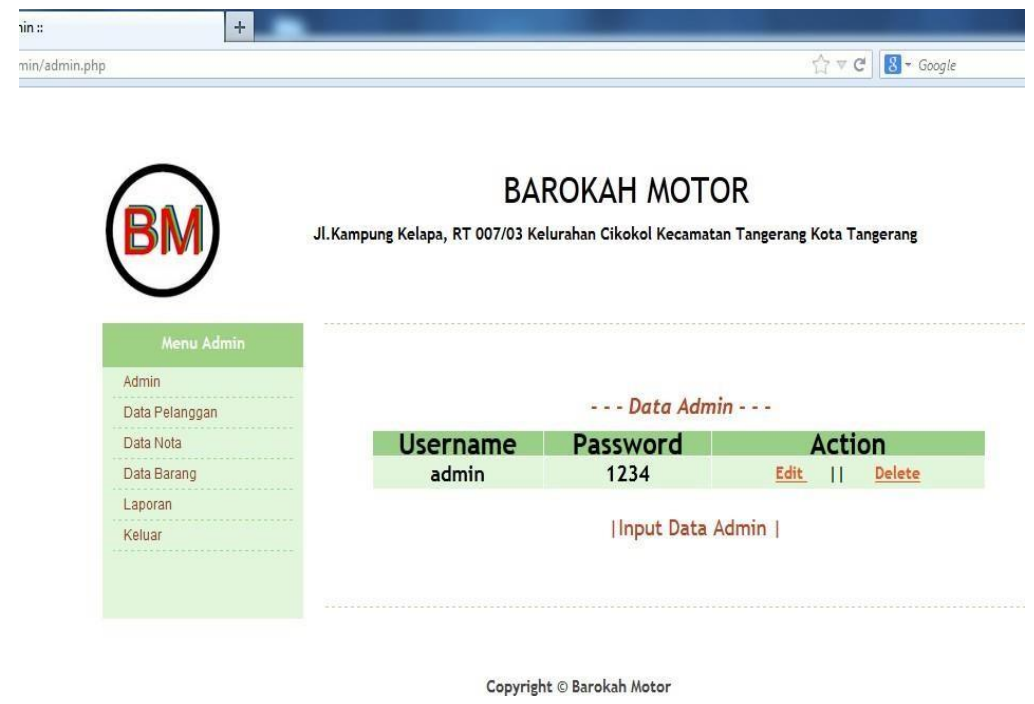

Gambar 6. Tampilan Menu Admin

Pada tampilan menu area admin merupakan isi dari beberapa menu yang akan di kelolah oleh admin untuk melakukan proses pengolahan data berdasarkan transaksi.

\section{c. Tampilan Menu Data Pelanggan}




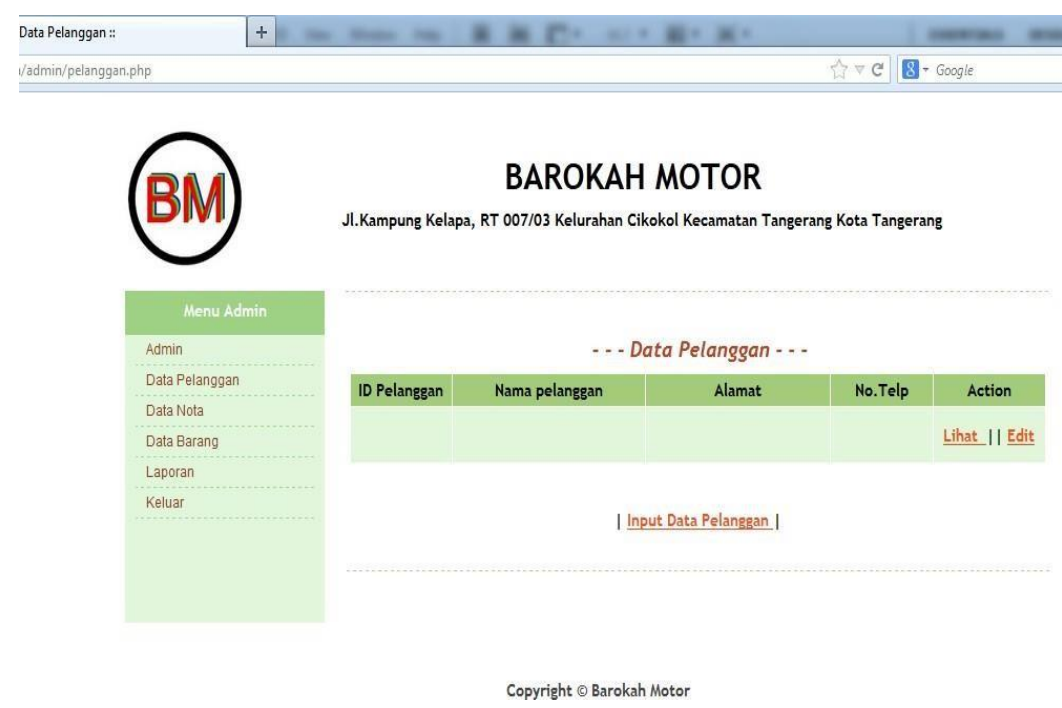

Gambar 7. Tampilan Menu Data Pelanggan

Dalam Gambar 7, terdapat tampilan data menu para pelanggan yang di data dan di input oleh admin setelah melakukan transakasi pembelian barang.

\section{d. Tampilan Menu Data Nota}
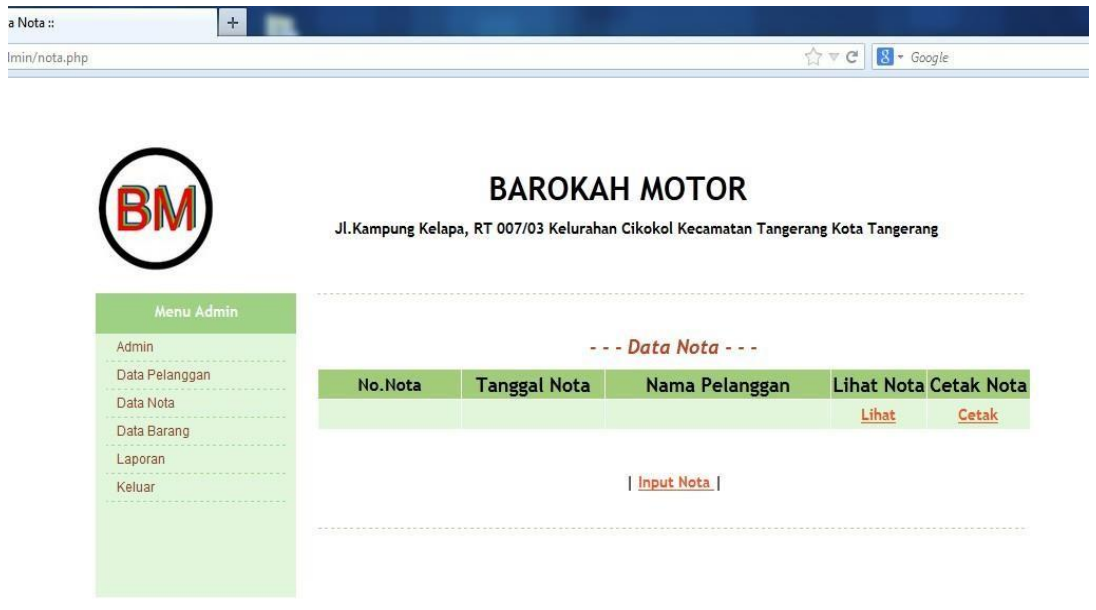

Copyright $\odot$ Barokah Motor

Gambar 8. Tampilan Menu Data Nota

Pada menu ini terdapat tampilan menu data Nota dari hasil transaksi penjualan yang di berikan kepada costomer

e. Tampilan Menu Data Barang 


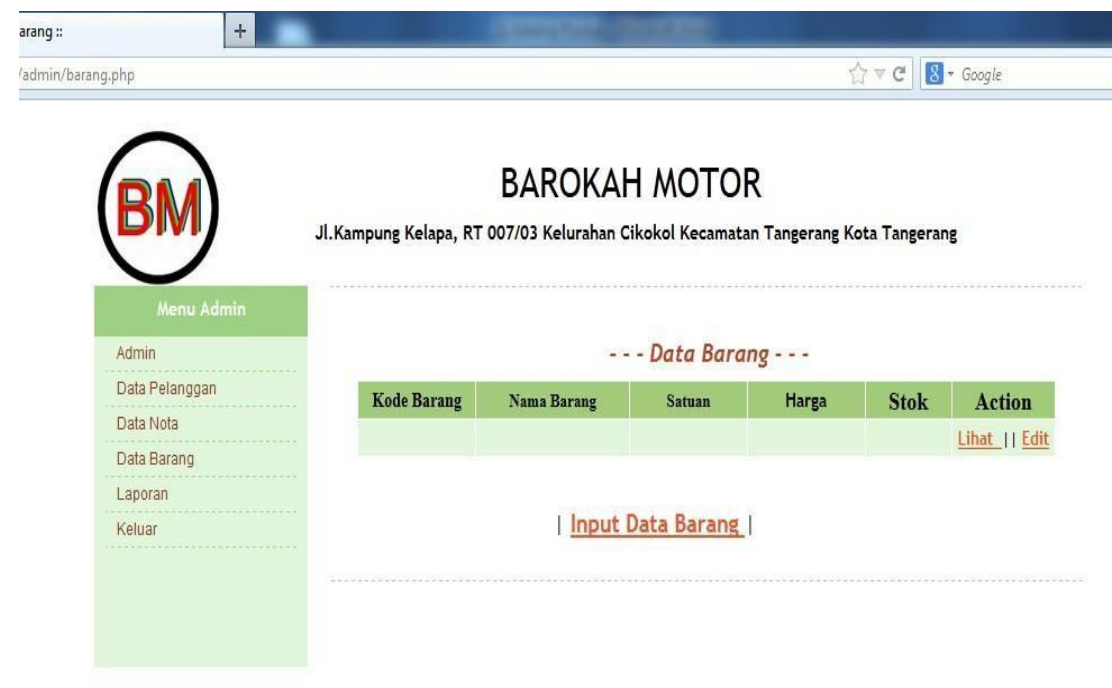

Copyright $\odot$ Barokah Motor

Gambar 9. Tampilan Menu Data Barang

Pada gambar 9,menampilkan data barang yang ada pada bagian gudang smua terdata dengan lengkap,sehingga jika admin ingin melakukan pengecekan stock barang dapat di lihat pada jumlah barang yang ada tertera pada menu tersebut.

\section{f. Tampilan Menu Laporan}
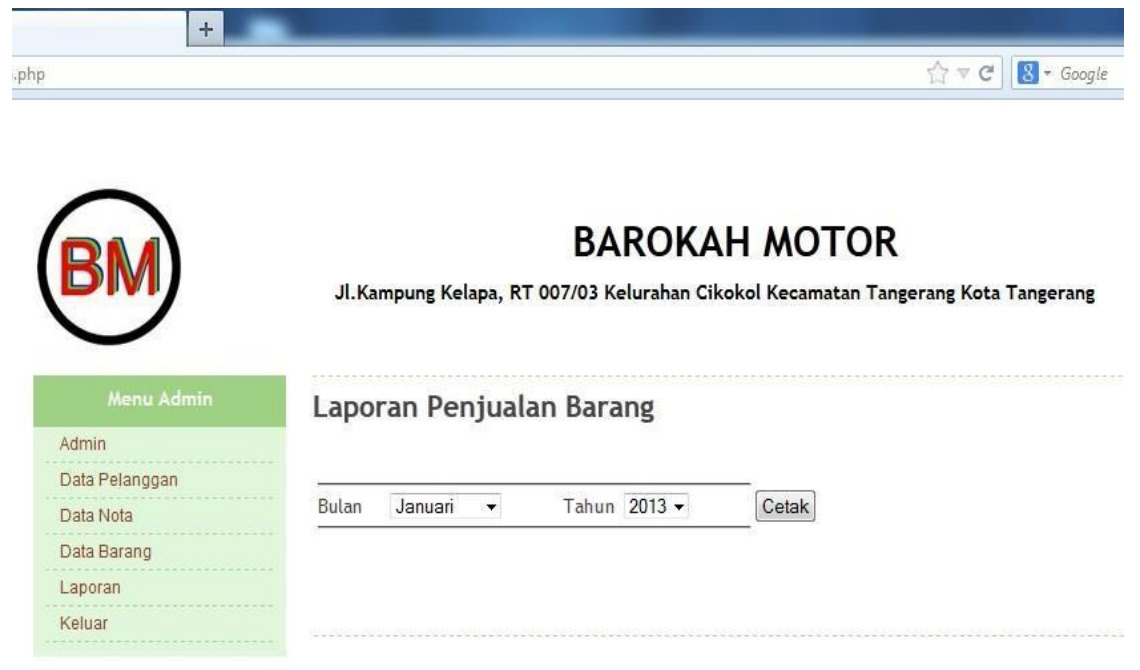

Copyright $\odot$ Barokah Motor

Gambar 10. Tampilan Menu Laporan

Pada gambar 10,menampilkan data menu laporan yang dapat di cetak oleh admin berupa laporan penjualan barang selama periode yang di inginkan. 


\section{KESIMPULAN}

Dari hasil Implementasi Aplikasi di lapangan dapat di lakukan pengukuran dari hasil jumlah Pelanggan yang datang di bengkel untuk melakukan transaksi pembelian,sebagai berikut:

Tabel 1.Grafik Pelanggan

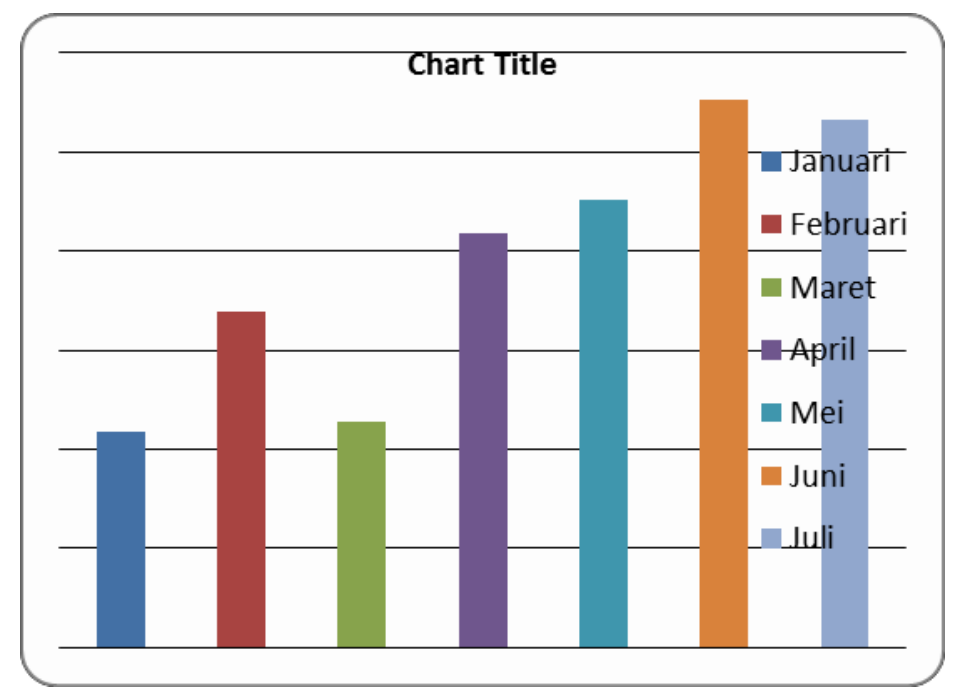

Dapat dijelaskan bahwa penelitian yang telah dilaksanakan di Bengkel Barokah Motor, serta berdasarkan uraian dan pembahasan pada bab-bab sebelumnya, maka penulis menyimpulkan. Dengan sistem penjualan sparepart motor yang dirancang dengan berbasis basis web, maka pemilik bengkel dapat memperoleh beberapa manfaat, seperti mempercepat proses kinerja bagian administrasi dalam memproses data, karena bagian administrasi hanya tinggal memasukkan data item apa saja yang dibeli oleh pelanggan. Mudahnya dalam pembuatan laporan, karena data-data transaksi sudah otomatis tersimpan sehingga bagian administrasi hanya tinggal memilih periode laporan penjualan yang hendak dicetak. Data yang terpelihara, karena sistem penjualan yang dirancang sudah menggunakan database. Mudah digunakan, karena dirancang dengan simple user interface menggunakan bahasa pemrograman PHP. User tidak perlu lagi mencatat setiap transaksi dan merekap data secara manual, karena sistem yang dibuat sudah sesuai requirement yang ada.User hanya mencari nama item yang dibeli dan menginput quantity pembelian pada menu transaksi. Sedangkan pada menu laporan, user hanya tinggal memilih periode bulan yang ingin dicetak/ditampilkan.Supaya sistem ini berjalan dengan baik kedepannya, maka user harus mengikuti pelatihan bagaimana sistem ini digunakan.Setelah sistem dapat digunakan dan dijalankan dengan efektif, maka perlu dilakukan kajian kembali sehingga tidak menutup kemungkinan untuk dilakukan suatu pengembangan sistem yang lebih baik.

Suatu system aplikasi yang sudah dibuat harus di gunakan dengan baik dan dikontrol dengan secara update. File-file yang ada perlu dibackup dan disimpan di tempat khusus, sehingga 
apabila ada kerusakan atau kehilangan data pada file-file utama tidak jadi masalah karena masih ada file cadangan.

\section{SARAN}

Dengan melihat kesimpulan terdapat kekurangan pada sistem Apilkasi Penjualan yang sedang diusulkan, hendaknya dicatat oleh user atau orang yang bersangkutan dengan sistem ini, hal ini ditujukan untuk perbaikan sistem agar menjadi lebih sempurna

\section{DAFTAR PUSTAKA}

[1] M.Leo Agung,. "Kupas Tuntas Adobe Dreamweaver CS 5 Dengan Pemrograman PHP Dan MySQL", Penerbit Andi Dan Madcoms. 2011

[2] Nugroho Adi, "Rekayasa Perangkat Lunak Menggunakan UML Dan JAVA", Penerbit Andi. 2010.

[3] Suhendar Yahya,. "Pedoman Penyelenggaraan Perpustakaan Sekolah", Edisi 1, Penerbit Kencana Jakarta. 2005 